\title{
Reformas administrativas do Estado: o caso da reestruturação promovida na Secretaria de Desenvolvimento Social de Minas Gerais
}

\section{Matheus Fernandes Nascimento Henrique Tangari Silva}

Fundação João Pinheiro, Belo Horizonte, MG - Brasil

Este estudo aborda a reforma administrativa em curso no Estado de Minas Gerais no ano de 2019, a partir da reestruturação administrativa promovida na Secretaria de Estado de Desenvolvimento Social (Sedese). O objetivo do trabalho é, a partir da compreensão das principais mudanças promovidas, analisar o impacto institucional da absorção de algumas temáticas no escopo de atuação da secretaria. Além do arcabouço teórico relacionado às reformas administrativas, buscou-se também apropriar a pesquisa das relações existentes na temática das mudanças organizacionais, considerando aspectos relacionados à gestão da mudança e resistência à mudança. Ao abordar as dimensões legal, estratégica e gerencial, o estudo avalia de forma positiva as alterações realizadas, sendo possível observar a capacidade gerencial de absorver as diferentes temáticas. Ressalvam-se, entretanto, alguns impactos negativos nos processos e, principalmente, a dificuldade de adequação orgânica, bem como a ausência de mecanismos de transição para a promoção da gestão da mudança.

Palavras-chave: reforma administrativa, mudança organizacional, gestão de políticas públicas 


\section{Reforma Administrativa del Estado: el caso de la reestructuración impulsada en la Secretaría de Desarrollo Social de Minas Gerais}

El estudio aborda la Reforma Administrativa en curso en el Estado de Minas Gerais en 2019, a partir de la reestructuración administrativa promovida por la Secretaría de Estado de Desarrollo Social (Sedese). El objetivo de este trabajo es, a partir del análisis de los principales cambios promovidos, analizar el impacto institucional de la absorción de algunos temas en el ámbito de actuación de la secretaría. Además del marco teórico relacionado con las reformas administrativas, también se buscó apropiarse de la investigación de las relaciones existentes sobre el tema del cambio organizacional, considerando aspectos relacionados con la gestión del cambio y la resistencia al cambio. Al abordar las dimensiones legales, estratégicas y gerenciales, el estudio evalúa positivamente los cambios realizados, y es posible observar la capacidad gerencial para absorber los diferentes temas. Sin embargo, hay algunos impactos negativos en los procesos y, especialmente, la dificultad de la adaptación orgánica, así como la ausencia de mecanismos de transición para promover la gestión del cambio.

Palabras clave: remodelación administrativa, cambio organizacional, gestión de políticas públicas

\section{Administrative reforms of the state: the case of restructuring promoted at the Secretariat of Social Development of Minas Gerais}

The study describes the process of the Administrative Reform occurred in the state of Minas Gerais in 2019, from the administrative restructuring promoted by the State Secretariat of Social Development (Sedese). The objective of the research is understanding the impact of the absorption of some themes in the scope of the institution, considering the changes promoted. In addition to the theoretical framework related to administrative reforms, it was also sought to appropriate the research of existing relationships on the theme of organizational change, considering aspects related to change management and resistance to change. The study positively evaluates the changes made from the managerial capacity presented in the absorption of different public policies. The legal, strategic and managerial dimensions were addressed to promote this evaluation. However, there are some negative impacts on the processes, especially, the difficulty of organic adaptation and the absence of transition mechanisms to promote change management.

Keywords: administrative reform, organizational change, public policy management 


\section{Introdução}

As reformas administrativas e os processos de mudança resultantes da adequação orgânica e funcional das instituições públicas são sempre objetos de pesquisas relevantes, buscando entender a aderência dos impactos aos objetivos inicialmente pretendidos, ou seja, a efetividade das alterações promovidas.

Conforme será abordado pelo trabalho, geralmente a intenção dessas mudanças tende a ter relação com a melhoria da prestação do serviço público através do ajuste fiscal e modernização da gestão. De forma legítima, transições de governo trazem comumente, também, alterações substanciais na gestão das instituições de maneira que os interesses dos grupos detentores do poder sejam considerados.

Este estudo busca contribuir para a análise desses processos de reforma, ao abordar a reforma administrativa do Estado de Minas Gerais promovida em 2019, na gestão do Governador Romeu Zema (Partido Novo). O objeto da pesquisa é, especificamente, a reestruturação administrativa ocorrida na Secretaria de Estado de Desenvolvimento Social (Sedese), decorrente desse processo de reforma. Buscou-se avaliar as profundas alterações na gestão das políticas públicas, já que a diretriz reformista era o enxugamento das instituições do Poder Executivo estadual.

Os efeitos das mudanças são apresentados na análise. Primeiramente, estabelecese o referencial teórico a partir das reformas administrativas e da mudança organizacional. Em seguida, apresentam-se as metodologias e documentos utilizados para promover a comparação entre as estruturas, atual e vigente, até o ano de 2018. A análise aborda três dimensões importantes, a saber: institucional-legal, estrutural gerencial, estratégia e diretrizes. Por fim, as conclusões são apresentadas de modo a convergir a análise dos impactos estruturais promovidos pela reestruturação administrativa.

\section{Os objetivos das reformas administrativas}

De acordo com March e Olsen (1988) apud Lima Júnior (1998), as mudanças na administração pública mais significativas, efetivas e duradouras foram introduzidas de forma gradativa, num processo de evolução natural, ao passo que grandes pacotes reformistas não se concretizaram, com resultados tímidos. Esta definição foi apresentada ao analisar o caso norte americano, com características de presidencialismo e executivo forte, semelhante ao Brasil. A conceituação de alguns pontos associados às reformas 
administrativas é relevante para a análise desse processo de reestruturação administrativa realizado no Estado de Minas Gerais em 2019, principalmente porque os ajustes orgânicos são recorrentes.

Os autores determinam alguns aspectos úteis para entender a natureza, o ritmo e as dificuldades dos processos de reforma. Primeiramente, existe algo como uma retórica comum da reforma, promoção de mudanças sempre em função da melhoria da efetividade e desempenho do setor público, sendo a reforma a solução unívoca para os problemas postos. No entanto, a relação entre as mudanças promovidas e os resultados é tênue, de modo que as mudanças refletem, em um ambiente democrático, os conflitos de interesses existentes e o dissenso é dado (LIMA JÚNIOR, 1998).

Outro aspecto relevante apontado na argumentação de Lima Júnior (1998) é em relação ao processo decisório e a complexidade do sistema político, que implica em relações de troca e barganha que ampliam ainda mais os conflitos existentes em contextos de reforma. Aponta-se, ainda, que as reformas não buscam promover a mobilização de todos os atores políticos envolvidos, considerando a quantidade e diversidade desses atores em ambiente de conflito ampliado, de modo que há a resistência declarada de atores que avaliam a mudança como prejudicial aos seus interesses. Por fim, o derradeiro aspecto apresentado reafirma o fato de que mudanças menores e graduais mobilizam mais facilmente para o aprofundamento da mudança, enquanto mudanças radicais tendem à desmobilização a médio e longo prazos (LIMA JÚNIOR, 1998).

Além disso, o autor analisa os processos de reforma do caso brasileiro, apontando que a maioria das propostas foram globais e não incrementais, sendo com frequência abortadas, e sem a obtenção dos resultados desejáveis, oscilando entre fortalecimento da administração direta e descentralização administrativa. Nesse sentido, Lima Júnior (1998) conclui que:

\footnotetext{
Independentemente de regime político e de governo, o país sempre conviveu com segmentos dispersos de uma burocracia weberiana em vários níveis da administração, interpenetrada e convivendo com um alto teor de patrimonialismo burocrático, nunca de fato completamente extirpado da administração pública. Contrapondo-se a essa administração, essencialmente amorfa, destacavam-se as "ilhas de excelência" [...] razoavelmente imunes ao processo político (LIMA JÚNIOR, 1998, p. 28).
}

Esses apontamentos do autor permitem prosseguir na discussão acerca das reformas administrativas, contrapondo questões que envolvem a burocracia na administração pública e, na perspectiva temporalmente posterior de outros autores, o gerencialismo. Bresser-Pereira (1996) apresentou críticas contundentes à administração 
pública burocrática ao discorrer sobre o processo reformista conduzido por ele no Governo Federal, em meados dos anos 1990.

A crise da administração pública burocrática tem raízes ainda no regime militar que não foi capaz de extinguir as características patrimonialistas, mas se agravou a partir do enrijecimento burocrático apresentado pela Constituição de 1988. De acordo com Bresser-Pereira (1996), a combinação entre patrimonialismo e enrijecimento burocrático ocasiona o alto custo e a baixa qualidade da administração pública. Sendo o objetivo da administração pública burocrática a superação do modelo patrimonialista, o pressuposto básico seria o aumento da eficiência. Entretanto, a "administração burocrática é lenta, cara, autorreferida, e pouco ou nada orientada para o atendimento das demandas dos cidadãos" (BRESSER-PEREIRA, 1996, p. 11).

Nesse sentido, considerando a expansão do Estado e as pressões da sociedade, a necessidade de uma administração pública gerencial fundamentava-se pelos problemas de complexidade e diferenciação de estruturas que buscariam responder as demandas, mas também a busca pela legitimação da burocracia frente a este cenário. Bresser-Pereira (1996) indica que os processos de mudança ocorrem nas dimensões institucional-legal através de leis e normas; na dimensão cultural, com base na alteração de valores burocráticos para gerenciais; e na dimensão gerencial, talvez a mais complexa, em que se buscaria oferecer serviços públicos de maneira mais eficiente através de novas ideias gerenciais.

A reforma gerida por Bresser-Pereira, de acordo com seu texto, teria por objetivo facilitar o ajuste fiscal, principalmente de estados e municípios, além de tornar mais eficiente e moderna a administração pública, direcionando-a para o atendimento dos cidadãos.

\footnotetext{
O objetivo geral da reforma administrativa será transitar de uma administração pública burocrática para a gerencial. Esta mudança, entretanto, não poderá ser realizada de um dia para o outro. Nem deverá ocorrer com a mesma intensidade nos diversos setores. Na verdade, a administração pública gerencial deve ser construída sobre a administração pública burocrática. Não se trata de fazer tábula rasa desta, mas de aproveitar suas conquistas, os aspectos positivos que ela contém, ao mesmo tempo que se vai eliminando o que já não serve (BRESSER-PEREIRA, 1996, p. 30).
}

Assim, além do ajuste claro direcionado para o funcionalismo público como medidas de curto prazo, a modernização administrativa para o aumento da eficiência buscaria combinar o fortalecimento da administração pública direta (núcleo estratégico) 
e descentralização com a criação de agências autônomas e organizações sociais geridas por contratos (BRESSER-PEREIRA, 1996).

Nascimento (2014), no âmbito de reestruturações administrativas pertencentes às reformas, resume esses pilares dos processos reformistas como corte ou redução de gastos do governo em relação ao ajuste fiscal, e mudanças nas estruturas organizacionais em relação à modernização institucional. Esses dois pilares seriam complementares e entendidos como o objetivo primário da mudança. $\mathrm{O}$ autor acrescenta que esses processos com foco em ajuste e modernização são incessantes e ocorrem em larga escala, como resposta às pressões políticas e da sociedade, de modo que as mudanças são realizadas com esse objetivo, sendo o caso do Governo de Minas Gerais, em diversas fases, exemplificação dessa teoria (NASCIMENTO, 2014).

\section{Os processos de mudança organizacional}

Expressivas intervenções no setor público ocorrem por meio das chamadas reformas ou modernizações administrativas. Souza (1994) problematiza, como grande questão a ser discutida no caso da área pública, se tais reformas podem de fato ser compreendidas e analisadas sob a égide do campo das mudanças organizacionais. Para o autor, baseando-se nos argumentos de Bertero (1976), mudanças sempre são ancoradas ao processo decisório e originam-se a partir de duas perspectivas complementares: a alteração na estrutura e modificações de cunho comportamental. Com base nessas premissas, então, o autor sugere que as decisões por reformar ou modernizar o Estado vão necessariamente levar a mudanças na organização (SoUZA, 1994).

A mudança é um processo decorrente da reação à ação de forças exercidas pelo meio onde as mesmas se encontram inseridas, que pode ocorrer por meio da alteração de posição no mercado, mudança da função social, modificação do direcionamento estratégico (missão, visão, objetivos estratégicos), mudança de valores, autoridade e responsabilidade (LOPES; STADLER; KOVALESKI, 2003).

De acordo com Silva, Araújo e Vaz (2009), a mudança organizacional é entendida como resultado do somatório de fatores internos e externos que afetam diretamente o funcionamento das organizações. Esses autores esclarecem que, entre as fontes externas, estão a ocorrência de eventos ambientais, como as oscilações do mercado e da concorrência, as reformulações políticas governamentais e as alterações em um grande 
grupo de empresas. No nível interno, por sua vez, as mudanças ocorrem devido à ação estratégica da alta administração, que objetiva reformular objetivos organizacionais a serem alcançados, à implantação ou aprimoramento de sistemas de planejamento e controle, além de situações originadas de processos interativos dos integrantes da organização. Cabe ressaltar, ainda, que a mudança também pode ocorrer por ações isoladas e arbitrárias exercidas pela alta cúpula da organização.

Há ainda o entendimento de que o processo de mudança organizacional está atrelado às alterações sofridas, ao longo do tempo, na maneira de se pensar gestão. Tal fato se dá tanto pelo surgimento de novos modelos e ferramentas de gestão, como pela própria evolução das correntes de pensamento em administração e gestão de organizações (RoNDEAU, 1999 apud SANTOS, 2014).

Bressan (2004), após abrangente revisão da literatura que versa sobre o tema, sintetiza que, ainda que haja essa heterogeneidade dos conceitos acerca da mudança organizacional, pontos comuns são observados, como, por exemplo, a existência de um planejamento por trás das mudanças propostas e o recorrente objetivo de aumentar o desempenho organizacional.

O conhecimento das razões da mudança, o gerenciamento do processo de mudança, a existência de um diagnóstico organizacional, a definição dos rumos impostos pela mudança, o estabelecimento de plano estratégico norteador e o constante monitoramento e avaliação do processo de mudança são, genericamente, algumas das questões essenciais para melhor compreensão da mudança organizacional (LOPES; STADLER; KOVALESKI, 2003).

Faz-se necessário adentrar nas tipologias de mudança organizacional apresentadas por Nadler e Tushman (1990), que distinguem as mudanças entre incrementais e estratégicas. A mudança incremental refere-se a componentes específicos da organização, visa à implementação nos fatores existentes para, assim, atribuir maior capacidade de crescimento, tendo como principais exemplos as pequenas reformulações estruturais, a introdução de novas tecnologias e ferramentas e a modificação de práticas de administração de pessoal. Por outro lado, as mudanças estratégicas reforçam o objetivo de modificar a organização como um todo, na medida em que redefinem a própria estratégia, a estrutura como um todo, as pessoas, os processos e, em algumas situações, valores que conceberam a organização. 
A liderança é um fator importante na mudança proposta, já que esses tipos de mudança organizacional acabam por exigir formas de conduzir diferentes. Mudanças entendidas como estratégicas não devem se apoiar em estruturas e processos já existentes, uma vez que eles são objetos da própria mudança. Assim, o sucesso dos processos de mudança depende inclusive de estruturas temporárias de transição coordenadas por lideranças capazes de transmitir motivação e um sentido de futuro para a organização, mobilizando os diferentes níveis de colaboradores (ACUNÃ; FERNANDEZ, 1995).

A gestão desse processo de mudança deve ter em seu escopo três elementos: conteúdo, pessoas e processos. O conteúdo diz respeito ao "o que" da organização que precisa ser alterado, ou seja, a estratégia, a estrutura, os processos, as tecnologias, as ferramentas, as práticas de trabalho, entre outros. O elemento das pessoas, que reflete o “quem", trata dos comportamentos, emoções, pensamentos e espíritos dos seres humanos que estão desenhando, implementando, suportando e sendo impactados direta ou indiretamente pela mudança. Por fim, os processos correspondem ao "como" as mudanças no conteúdo e nas pessoas são planejadas, desenhadas e implementadas. O processo, nesse sentido, engloba as ações que produzirão as mudanças no conteúdo e nas pessoas constituintes do ambiente organizacional (ANDERSON; ANDERSON, 2001 apud SANTOS, 2014).

Para Santos (2014), os processos de mudança são gerenciados, muitas vezes, de forma menos eficiente do que realmente poderiam ser, na medida em que alguns aspectos relevantes ao processo de mudança não são levados em consideração por algumas organizações. Um processo de mudança organizacional eficiente deve seguir os seguintes passos essenciais: (1) o reconhecimento da necessidade da mudança, através da identificação de fatores externos ou internos que exijam determinada alteração do status quo; (2) o desenho inicial da mudança proposta, no sentido de transformar a necessidade reconhecida em um estudo e análise de viabilidade; (3) o diagnóstico da situação vigente e a projeção da situação futura, no sentido de relacionar causas aos problemas e identificar deficiências e oportunidades para o processo; (4) planejamento da implementação, materializado nos planos de ação para a mudança proposta; (5) a implementação da mudança em si, com a execução e monitoramento constante do plano de ação, bem como dos resultados que surgem da operacionalização do mesmo; e (6) a revisão e consolidação da mudança, no sentido de fornecer feedbacks para processos futuros e recompensas pelos resultados obtidos (SANTOS, 2014). 
A organização American Productivity Quality Center (APCQ), em 1997, analisou as melhores práticas de operacionalização do processo de mudança em empresas americanas e identificou cinco elementos-chave responsáveis pelo seu êxito: (1) comprometimento e participação ativa do líder; (2) alteração fundamental na cultura da organização; (3) envolvimento ativo dos empregados, propiciando-lhes autonomia e participação direta no procedimento; (4) métricas e comunicação efetivas na organização; e (5) alinhamento e responsabilidade do sistema de recursos humanos com as metas e objetivos da mudança. Diante do exposto, torna-se claro que mudanças organizacionais exigem uma considerável mobilização de toda a organização quanto à sua necessidade e devem ser conduzidas pela figura de um líder, figura fundamental no processo e na mobilização dos indivíduos. Além disso, quanto mais transparente, comunicativo e democrático, no sentido de permitir a participação de todos os envolvidos nas decisões a serem tomadas, maiores são as chances de êxito do processo de mudança proposto (BRESSAN, 2004).

\section{Cultura organizacional e resistência à mudança}

Para Migueles, Lafraia e Costa (2006), cultura organizacional pode ser compreendida como um mecanismo de coordenação informal, com relevante impacto sobre os custos de transação internos e externos à organização. A cultura, então, funciona como uma lente que molda as percepções das pessoas acerca da realidade vivenciada, dando-lhe significado. Santos (2014) apresenta a definição, de relevante notoriedade na literatura que versa sobre o tema, oriunda do estudo de Schein (1985), da cultura organizacional como

[...] o conjunto de pressupostos básicos que um grupo inventou, descobriu ou desenvolveu, ao aprender como lidar com os problemas de adaptação externa e integração interna e que funcionam bem o suficiente para serem considerados válidos e ensinados a novos membros como forma correta de perceber, pensar e sentir, em relação a esses problemas (SCHEIN, 1985 apud SANTOS, 2014, p. $6)$.

A influência da cultura organizacional no contexto das mudanças é abordada por Fleury (1989), que estabelece que a dinâmica social do grupo é regida por fatores que tanto podem facilitar como dificultar um processo de mudança, podendo explicar tanto o sucesso ou fracasso de uma adaptação necessária, como as consequências desta para o próprio grupo. 
Se durante um processo de mudança não houver o preparo da equipe, no sentido de evitar a emergência de receios e dúvidas, corre-se o risco do aparecimento de grandes instabilidades no clima organizacional e, consequentemente, de aumento dos focos de resistência à mudança. Apesar de notoriamente importantes para a sobrevivência da organização, as mudanças causam diferentes tipos de reação nos atores organizacionais, que variam de uma adesão imediata e posterior comprometimento à proposta de mudança, à resistência completa a qualquer tipo de mudança (BRESSAN, 2004; SANTOS, 2014).

Para Bressan (2004), a reação mais comum à mudança organizacional é a resistência. A resistência individual está relacionada às características subjetivas e pessoais, enquanto a resistência organizacional diz respeito à inércia estrutural e do grupo, à falta de liderança na condução do processo e às percepções de ameaça em relação aos grupos informais instalados (BRESSAN, 2004).

O estudo de Marques et al. (2014), analisou a resistência à mudança de servidores públicos do Governo de Minas Gerais no âmbito do denominado choque de gestão, que consistiu em uma importante reforma administrativa no Poder Executivo estadual à época. Em relação às causas da resistência à mudança, os resultados deste estudo apontam para a indecisão com o processo de mudança como o principal fator motivador de tal reação por parte dos servidores. Extrai-se que, quando o indivíduo está indeciso em relação às vantagens da mudança, ele tornar-se-á resistente, nesse caso, à alteração proposta, até que seja possível perceber as modificações como benéficas para si e para e organização como um todo. A pressão do grupo em que está inserido aparece como segundo principal fator ligado à resistência à mudança, na medida em que o indivíduo se sente desencorajado e às vezes oprimido pelos colegas de trabalho em relação à aceitação de inovações propostas ou até mesmo a mudanças em suas práticas de trabalho. Por fim, como terceiro principal fator associado à resistência, aparece a ameaça ao convívio social, que reside na apreensão do indivíduo em ter que deixar o habitual grupo de trabalho ou ainda ter que conviver com colegas de trabalho que não lhe são agradáveis.

Faz-se necessário, no entanto, desmitificar o entendimento de que a resistência à mudança é algo natural e inevitável. O estudo de Hernandez e Caldas (2001), que se contrapõe ao mito supracitado, esclarece que não é possível elaborar receituários de como lidar com a reação dos empregados às mudanças, na medida que o que de fato interessa é chamar a atenção dos gestores sobre a necessidade de conhecer os indivíduos afetados e a cultura da organização, com o objetivo de planejar as mudanças e saber lidar com as 
mais diferentes reações apresentadas. Nesse sentido, os autores sustentam que tão importante quanto a análise das causas da resistência, particularmente para a mudança organizacional, é a identificação dos grupos e indivíduos que terão maior inclinação a resistir à mudança e das razões desse comportamento.

É possível observar, então, que não existe fórmula exata para se tratar e minimizar a resistência à mudança nas organizações, seja pelos indivíduos ou pelo contexto estrutural e organizacional em si. No entanto, planejar e desenvolver estratégias, bem como conhecer os indivíduos e a cultura do local em que se realiza a mudança são aspectos que devem ser observados na metodologia da mudança, visto que são capazes de auxiliar na obtenção dos resultados esperados (BRESSAN, 2004).

Enfim, estruturou-se o referencial teórico a partir da perspectiva das reformas administrativas e os consequentes processos de mudança organizacional provocados. Essas definições permitem o entendimento acerca das questões envolvidas na reestruturação administrativa que será analisada neste trabalho.

\section{Objeto de análise da reforma administrativa e a metodologia de pesquisa}

O processo de reforma administrativa foco deste estudo se iniciou com a transição de governo, até mesmo antes do início de 2019, onde o plano de governo vencedor das eleições declarou a redução da estrutura administrativa do Estado. As mudanças foram promovidas com a colaboração de consultorias especializadas e, em 30 de maio, a lei da reforma foi aprovada, após intensa negociação entre os Poderes Executivo e Legislativo.

Este estudo analisa os aspectos legais, estratégicos e de gestão que envolvem a reestruturação administrativa da Secretaria de Desenvolvimento Social (Sedese), fruto da reforma administrativa citada. As diretrizes e resultados até então mensurados são apresentados a partir da análise de documentos oficiais vigentes até o fim do exercício de 2018, que dizia da configuração da instituição, bem como de informações atualizadas do exercício de 2019, durante a efetivação das mudanças organizacionais realizadas para adequação à reforma administrativa.

A análise documental, no presente estudo, avaliou, para além dos decretos de competências e leis orgânicas da estrutura administrativa do estado, a estrutura programática do orçamento nos Planos Plurianuais de Ação Governamental (PPAGs), o 
organograma da secretaria antes e depois das mudanças e os objetivos e diretrizes estratégicas declaradas em instrumentos institucionais internos.

Outrossim, a investigação implementada fez-se valer da perspectiva metodológica da pesquisa-ação. Segundo Engel (2000), a pesquisa-ação é um tipo de investigação participante que desenvolve conhecimentos e percepções a partir da prática. O pesquisador, sob essa perspectiva, é considerado um praticante social do objeto em estudo e, consequentemente, está inserido nos grupos sociais e procedimentos administrativoorganizacionais que serão analisados. Nesse sentido, os autores do presente estudo atuam na execução das políticas públicas da Sedese e tiveram direto envolvimento nas discussões e decisões tomadas no âmbito do processo de reestruturação em questão. Tal fato, por sua vez, foi de suma importância para a edificação das percepções sobre a condução do processo em questão, principalmente no que diz respeito à governança e às rotinas que operacionalizaram o diálogo entre atores e instituições envolvidas.

Finalmente, a análise foi promovida no sentido de comparar as informações das estruturas anterior e atual da Sedese, buscando avaliar os efeitos do processo de adequação e reestruturação administrativa. A maioria dos aspectos abordados estão em constante atualização, uma vez que as mudanças promovidas são relativamente recentes. No entanto, já é possível observar alguns impactos da reforma, não só no âmbito da Sedese, mas também no que diz respeito à atuação do poder público estadual em Minas Gerais.

\section{O impacto da reestruturação administrativa}

Considerando a dimensão funcional das instituições públicas e a absorção do impacto das mudanças organizacionais promovidas pela transição de governo e reestruturação administrativa, busca-se aqui apresentar os principais elementos que, de alguma forma, foram influenciados nesse processo. Inicialmente, abordam-se questões relativas ao aspecto formal da reforma no âmbito da reestruturação administrativa ocorrida na Secretaria de Estado de Desenvolvimento Social de Minas Gerais (Sedese), ou seja, a avaliação acerca das competências definidas em leis e decretos. Posteriormente, são apresentadas as questões pertinentes à estrutura que foi reorganizada e readequada e, finalmente, os aspectos envolvidos na estratégia adotada pela nova secretaria constituída, conforme ilustra a Figura 1. 
Figura 1 - Modelo analítico do processo de reestruturação administrativa da Sedese - 2019

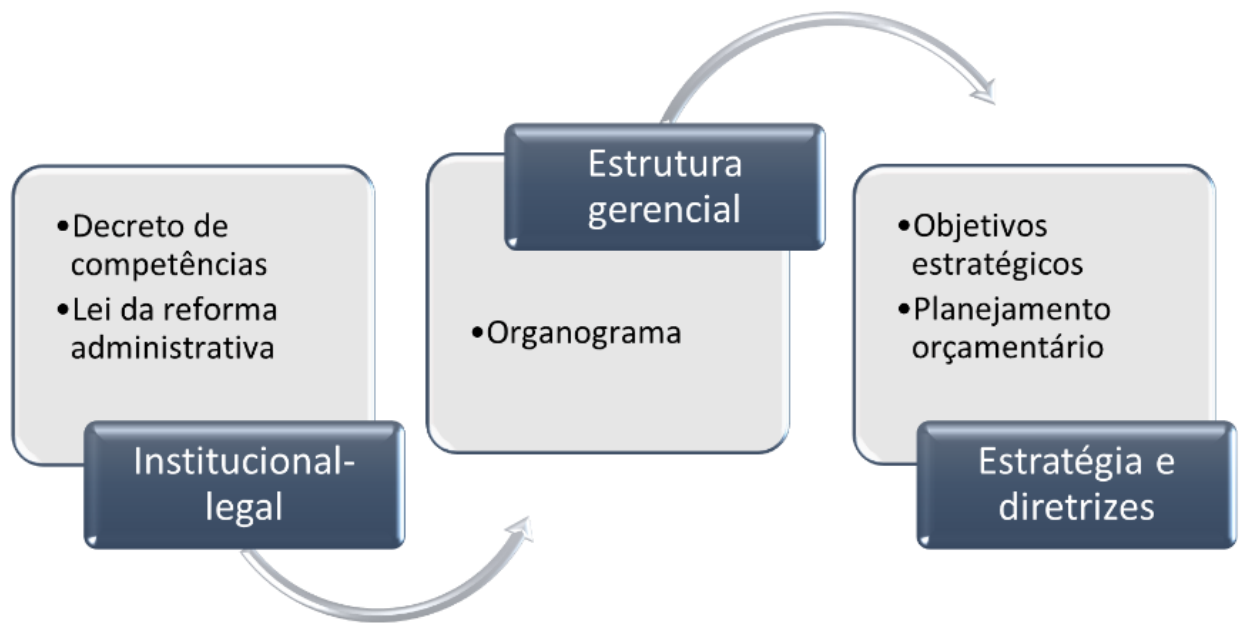

Fonte: Elaboração pelos autores.

Esse modelo foi traçado com base na disponibilidade informacional do processo de transição promovido pela reforma administrativa, mas a adequação faz um breve paralelo com as dimensões definidas por Bresser-Pereira (1996), descritas anteriormente, entendendo a dimensão institucional-legal como alicerce para as definições estruturais da gestão e a estratégia de atuação das políticas públicas.

\section{Dimensão institucional-legal}

O Decreto $\mathrm{n}^{\mathrm{o}} 47.067$, de 21 de outubro de 2016, que dispõe sobre a organização da Secretaria de Estado de Trabalho e Desenvolvimento Social, apresenta como competência o planejamento, execução, controle e avaliação das ações da política da assistência social, do desenvolvimento social da população através do enfrentamento da pobreza e da vulnerabilidade social, além do fomento das políticas de trabalho, emprego e renda e da política de atendimento às medidas socioeducativas (MINAS GERAIS, 2016).

$\mathrm{Na}$ estrutura orgânica, além das subsecretarias de assistência social e trabalho e emprego, cada uma com suas respetivas superintendências e diretorias, vinculadas ao gabinete, estão as superintendências de programas especiais; planejamento, gestão e finanças; e regionalização, além das assessorias jurídica, de planejamento, comunicação social e a unidade setorial de controle interno (MinAS GERAIS, 2016). A análise comparativa das estruturas e organogramas virá adiante, porém, apresentam-se aqui as definições estabelecidas nos dispositivos legais que embasavam a atuação da instituição. 
O decreto apresenta ainda a abrangência territorial das diretorias regionais vinculadas à secretaria e conselhos vinculados, além de definir as competências de cada área específica que compõe a estrutura da Sedese. Este decreto regulamentou a Lei $\mathrm{n}^{\mathrm{o}}$ 22.257, de 27 de julho de 2016, que estabeleceu a estrutura orgânica da administração pública do Poder Executivo do estado.

No âmbito do processo de reforma ocorrido em 2019, além do Decreto nº 47.761, de 20 de novembro de 2019, que dispõe sobre a organização da Secretaria de Desenvolvimento Social, esta análise considera também as definições da Lei nº 23.304, de 30 de maio de 2019, que atualiza a estrutura orgânica do Poder Executivo do estado e dá outras providências.

No art. 26 da referida legislação, as competências da Sedese incluem as políticas de assistência social, trabalho e emprego, enfrentamento da pobreza, segurança alimentar e nutricional, direitos humanos, esporte e lazer, habitação, medidas socioeducativas e promoção do atendimento ao dependente químico. Nota-se, comparativamente, a inclusão de pautas de políticas públicas relevantes que anteriormente compunham a estrutura de outras secretarias. O art. 27 vai apresentar, ainda, a estrutura das subsecretarias vinculadas e suas respectivas políticas públicas, até o nível de superintendência, além dos conselhos vinculados (MINAS GERAIS, 2019a).

Em relação ao decreto de competência da nova organização da Sedese, são apresentadas as estruturas orgânicas da secretaria, considerando as políticas identificadas no escopo da sua atuação. Além das subsecretarias setoriais, o decreto vincula ainda assessorias, conselhos de políticas públicas, unidades regionais e entidades vinculadas, com suas respectivas competências (MINAS GERAIS, 2019b).

\section{Dimensão da estrutura gerencial}

No contexto da reforma administrativa em questão, a fusão estrutural de três Secretarias de Estado (Trabalho e Desenvolvimento Social, Direitos Humanos e Esportes) e uma Subsecretaria (de Políticas sobre Drogas) aparece como um processo de grande complexidade, tendo em vista a necessidade de compatibilizar o número de unidades administrativas e técnicas ao número de cargos disponíveis, sem que, no entanto, seja comprometido o nível de entregas e qualidade dos serviços ofertados.

A estrutura orgânica da Sedese até o exercício 2018, formalizada pelo decreto de competências, contava com duas Subsecretarias (de Assistência Social e de Trabalho e 
Emprego), 9 superintendências, 32 diretorias e 22 diretorias regionais em todo o Estado de Minas Gerais.

Sob a égide da reestruturação promovida pela lei da reforma administrativa e regulamentada pelo decreto de competências, a Sedese passou a contar com cinco Subsecretarias (Assistência Social, Trabalho e Emprego, Direitos Humanos, Esportes e Políticas sobre Drogas), 13 superintendências e 32 diretorias, além da manutenção das 22 diretorias regionais. No entanto, se fossem somadas as unidades técnico-administrativas dos órgãos fundidos, conforme seus respectivos organogramas do exercício de 2018, seriam contabilizadas o número original de 26 superintendências e 75 diretorias.

Extrai-se, da análise estrutural do novo organograma, que o processo de reestruturação seguiu as diretrizes emanadas pelo setor central do governo empossado no exercício 2019, no sentido de prover cortes na estrutura do aparato governamental. A considerável redução do número de superintendências (50\%) e diretorias (57\%) vinculadas à Sedese, em relação às estruturas que os órgãos agora reunidos possuíam até o exercício de 2018 , consiste em uma importante conquista do processo, na medida em que traduz a exitosa atuação no redesenho institucional e na redistribuição de competências entre as unidades técnico-administrativas.

\section{Dimensão estratégia e diretrizes}

A partir das novas competências absorvidas pela Sedese, iniciou-se o processo de definição estratégica da atuação e condução das políticas públicas sob a responsabilidade da pasta, seguindo inclusive as orientações estratégicas do nível central de governo, onde foram definidas bandeiras e objetivos estratégicos que se traduziram em programas prioritários. No caso da Sedese, o destaque é para o objetivo de "Reduzir a pobreza incentivando a jornada para autonomia”. Não se avalia aqui a condução da reforma no nível estratégico de governo, mas sim seus efeitos e desdobramentos setoriais para a Secretaria de Estado de Desenvolvimento Social (Sedese).

Analisando documentações internas disponibilizadas, é possível verificar que a diretriz adotada é de induzir as políticas, através do papel de facilitador, buscando a promoção da autonomia das pessoas, ou seja, capacidades e liberdades dos indivíduos e famílias. Considerando o conjunto das políticas públicas, as autonomias seriam o acesso à renda, oportunidades, liberdades, cidadania, qualidade de vida, entre outros aspectos, sempre visando à superação da situação de vulnerabilidade, também com um olhar 
múltiplo. A representação gráfica dessas definições apresenta-se a seguir na Figura 2.

\section{Figura 2 - Estratégia e identidade organizacional da Sedese, 2019}

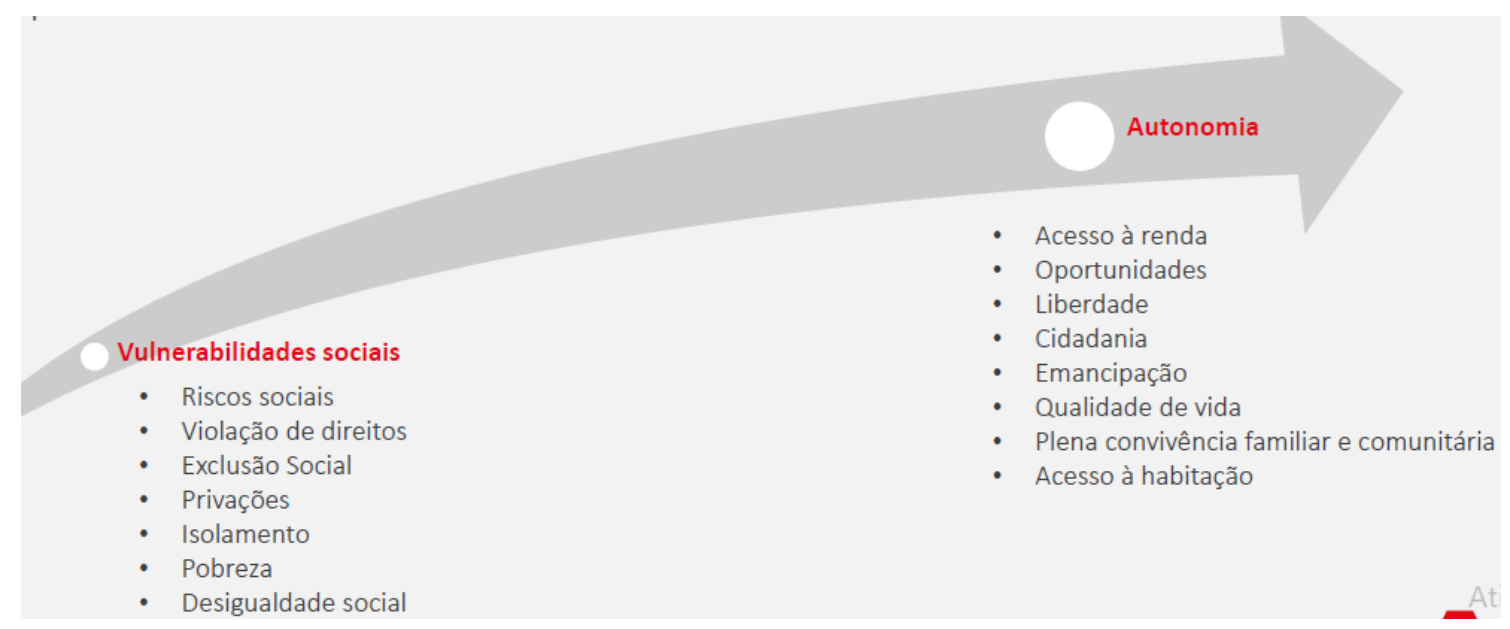

Fonte: Documentação interna, Sedese, 2019.

Dessa forma, a visão da instituição é de buscar um Estado mais desenvolvido, sendo reconhecido como referência na promoção de políticas sociais. Anteriormente, esperava-se que a Sedese fosse reconhecida através da melhoria dos indicadores sociais, reduzindo desigualdades e ampliando oportunidades. A promoção da proteção socioassistencial com a inclusão social e produtiva das famílias, efetivando o controle social e a descentralização das políticas era declarada como a responsabilidade da secretaria. Ambas as informações também estão disponíveis em documentos da instituição.

Comparativamente, os objetivos estratégicos anteriores e atuais possuem direcionamentos semelhantes, assim como a identidade organizacional mencionada acima, mostrando que de alguma forma há coerência na definição da condução das políticas públicas. Nota-se ainda que, a despeito da absorção de outras políticas públicas no processo de reforma, são contabilizados mais objetivos estratégicos anteriormente, $\mathrm{o}$ que indica, em alguma medida, o detalhamento maior da atuação permitido pelo escopo reduzido em comparação. É possível que seja resultado dos processos de planejamento, uma vez que em 2019 não se observou processo participativo envolvendo as áreas da instituição, tal como feito anteriormente.

A partir do desdobramento do planejamento, considerando o Plano Plurianual de Ação Governamental (PPAG), analisando as versões 2016-2019 e 2020-2023, disponíveis no endereço eletrônico de Assembleia Legislativa e Secretaria de 
Planejamento e Gestão, observa-se que a Sedese ampliou seu quantitativo de programas e ações, obviamente em função da absorção de outras políticas públicas. Na estrutura atual eram 12 programas e 31 ações. Na proposta para 2020, que se encontra em análise legislativa, são 17 programas e 51 ações. No entanto, se somarmos os programas e ações das políticas sobre drogas, esportes, direitos humanos, e segurança alimentar e nutricional, seriam 20 programas e 72 ações orçamentárias.

Sendo assim, pode-se concluir que a junção das políticas refletiu em redução da estrutura programática da secretaria e suas prioridades, condensando também a disponibilidade orçamentária. Restringiu-se a apresentação dos valores e da análise dos quantitativos orçamentários em função da perspectiva de crise fiscal e redução constante das receitas destinadas aos programas orçamentários, inclusive induzindo metodologias de orçamento base zero. Não foram analisadas, ainda, as metas estratégicas dos programas prioritários, uma vez que elas estão em construção neste governo.

\section{Conclusões e considerações finais}

A reforma administrativa promovida pelo Governo de Minas Gerais no ano de 2019 foi analisada neste trabalho no intuito de buscar entender as questões relacionadas às mudanças provocadas e alguns de seus efeitos. Conforme previsto nos objetivos do trabalho, analisar a reforma no âmbito da Secretaria de Estado de Desenvolvimento Social (Sedese) permitiu criar conclusões sobre determinados aspectos particulares ao caso, sendo que as lições aprendidas trazidas neste texto podem contribuir para futuras reestruturações administrativas.

Após toda a análise teórica da relação, no âmbito do setor público, das reformas administrativas e da consequente mudança organizacional promovida, bem como uma contextualização do caso específico do governo do Estado de Minas Gerais em relação às mudanças, apresentaram-se os aspectos particulares relacionados ao caso da Sedese, no que diz respeito às dimensões institucional-legal, estrutura gerencial e estratégia e diretrizes.

De início, causa estranheza o fato de a definição estrutural ter se dado em momento anterior à construção da estratégia do órgão, tendo em vista o considerável risco que tal realidade traz para a condução da reforma, principalmente no que diz respeito à 
possibilidade de não convergência da estrutura proposta e das diretrizes de atuação apropriadas a partir da estratégia da instituição.

Não foi observada, no contexto da reestruturação administrativa, a formação de um grupo ou comissão de transição designada especificamente para o processo. As decisões, e posteriores consequências estruturais e programáticas, foram tomadas no âmbito da alta gerência do órgão, sem a participação das áreas finalísticas sob responsabilidade da pasta, com reflexos possíveis no entendimento dos atores em relação à mudança.

A partir do referencial teórico trazido, o não envolvimento de atores organizacionais é tido como equívoco frequente nos processos de mudança, na medida em que ignora o indispensável papel da comunicação para a diminuição das incertezas, instabilidade e, por consequência, da resistência à mudança. Por tal fato, foi possível observar, nos primeiros meses, certa inércia produtiva na execução das atividades dos colaboradores. Não se considerou clara resistência, mas sim um clima organizacional em processo de adequação, aguardando a nova configuração de equipes e diretrizes necessária para a execução dos projetos.

Outra dificuldade percebida foi a não atenção aos aspectos mais operacionais que viriam a se alterar com a fusão organizacional das pastas, principalmente no que diz respeito aos processos integrados que foram prejudicados e geraram efeitos negativos diretos na execução das políticas públicas da pasta. Trata-se das unidades responsáveis pelas atividades-meio do órgão, principalmente no âmbito da Superintendência de Planejamento, Gestão e Finanças e da Assessoria Jurídica, que atuam em um contexto de sobrecarga de demanda pelo acréscimo de demandas das áreas finalísticas e inexistência de fluxos processuais pactuados junto às demais áreas, segundo as informações levantadas na pesquisa. Este é um fator de grande importância e que, consequentemente, deveria ter sido incluído no processo de planejamento e de transição das mudanças realizadas.

A compatibilização das estruturas organizacionais de três secretarias de Estado e uma subsecretaria em um único organograma, além da agregação de competências de naturezas variadas, foi missão dada pelas diretrizes de governo. O desafio consistiu na missão de garantir a continuidade das políticas públicas frente ao quadro de restrição fiscal e consequente necessidade de redução da estrutura do governo. Até o momento, a 
despeito do processo de maturação dos processos na nova estrutura, tem sido possível promover a manutenção dos serviços ofertados.

Apesar de alguns equívocos na condução dos processos inerentes à restruturação, principalmente ligados à centralização das discussões no alto escalão organizacional e seus reflexos nos descompassos operacionais da estrutura, tem-se, até o momento, a prevalência dos impactos positivos. A Sedese, nesse sentido, conseguiu atender as requisições do nível central de governo, no que diz respeito ao enxugamento da estrutura funcional, sem que, no entanto, fossem comprometidas as atuações estratégicas ou descontinuadas as políticas públicas das pastas consolidadas em sua estrutura.

Vale ressaltar alguns dos limites a que se propôs este trabalho. O curto prazo para viabilização da reforma administrativa, que se deu no final do quinto mês do governo Zema em Minas Gerais, foi delimitado por necessidades políticas, assim como a maioria dos processos de mudanças ocorridos no âmbito da administração pública estadual. Não era objetivo do estudo avaliar a viabilidade, necessidade ou formato político da mudança, muito menos a posterior eficiência posta em termos quantitativos e qualitativos, até mesmo pela limitação temporal, de modo que este é um campo de pesquisa que pode ser tratado em trabalhos futuros que se interessem pela temática.

\section{Referências}

ACUÑA, Eduardo; FERNÁNDEZ, Francisco. Análise de mudanças organizacionais: utilidades para políticas sociais. Revista de Administração Pública, v. 29, n. 2, p. 80-109, 1995.

BRESSAN, Cyndia Laura. Mudança organizacional: uma visão gerencial. Seminário de gestão de negócios, v. 1, 2004.

BRESSER-PEREIRA, Luiz Carlos. Da administração pública burocrática à gerencial. Escola Nacional de Administração Pública (ENAP). Revista do Serviço Público - RSP, ano 47, v. 120, n. 1, p. 07-40. Brasil. 1996.

ENGEL, Guido Irineu. Pesquisa-ação. Educar em Revista, n. 16, p. 181-191, 2000.

Fleury, Maria Tereza Leme. Desvendar a cultura de uma organização: uma discussão metodológica. In: FLEURY, Maria Tereza Leme; FISCHER, Rosa María. Cultura e poder nas organizações. Atlas, 1989.
HeRnANDEZ, José Mauro da Costa; CALDAS, Miguel P. Resistência à mudança: uma revisão crítica. Revista de Administração de Empresas, v. 41, n. 2, p. 31-45, 2001.

LIMA JÚNIOR, Olavo Brasil de. As reformas administrativas no Brasil: modelos, sucessos e fracassos. Escola Nacional de Administração Pública (ENAP). Revista do Serviço Público RSP, ano 49, n. 2, p. 5-32. Brasil. 1998.

LOPes, Paulo Cesar Barbosa; StAdLeR, Carlos Cezar; KovalesKI, João Luiz. Gestão da mudança organizacional. Publicatio UEPG: Ciências Humanas, Linguística, Letras e Artes, v. 11, n. 1, 51-57, jun. 2003.

Marques, Antônio Luiz; Borges, Renata; MorAIS, Kelly; SILVA, Mariane Coimbra. Relações entre resistência à mudança e comprometimento organizacional em servidores públicos de Minas Gerais. Revista de Administração Contemporânea, v. 18, n. 2, p. 161-175, 2014. 
Migueles, Carmen Pires; LAFRAiA, João Ricardo Barusso; SouzA, Gustavo Costa de. Criando o hábito da excelência: compreendendo a força da cultura na formação da excelência em SMS. Rio de Janeiro: Qualitymark, Petrobras, 2006.

MinAs Gerais, Decreto 47067 de 21/10/2016 Texto atualizado; Dispõe sobre a organização da Secretaria de Estado de Trabalho e Desenvolvimento Social. Disponível em: https://www.almg.gov.br/consulte/legislacao/co mpleta/completa-novamin.html?tipo=DEC\&num $=47067 \&$ ano $=2016$. ALMG. 2016.

MinAs GERAIS, Lei 23304 de 30/05/2019 - Texto original; Estabelece a estrutura orgânica do Poder Executivo do Estado e dá outras providências. Disponível em: https://www.almg.gov.br/consulte/legislacao/co mpleta/completa-nova-

min.html?tipo $=$ LEI $\&$ num $=23304 \&$ comp $=\&$ ano $=2019 \&$ texto $=$ or $\%$ E2\%80\%A6. ALMG. 2019a.

MinAs GeraIS, Decreto 47761 de 20/11/2019 Texto original; Dispõe sobre a organização da Secretaria de Estado de Desenvolvimento Social. Disponível em: https://www.almg.gov.br/consulte/legislacao/co mpleta/completa-novamin.html?tipo=DEC\&num=47761\&comp=\&an o=2019\&texto=original. ALMG. $2019 \mathrm{~b}$.

NADLER, David A.; TUSHMAN, Michael L. Beyond the charismatic leader: leadership and organizational change. California Management Review, v. 32, n. 2, p. 77-97, 1990.

NASCIMENTO, Matheus Fernandes. Reforma administrativa do Estado: análise do processo de

\section{Matheus Fernandes Nascimento}

iD https://orcid.org/0000-0003-2113-8829

Mestrando em Administração Pública na Fundação João Pinheiro, Especialista em Gestão da Informação e Pessoas pela Universidade Federal de Minas Gerais (UFMG) e Bacharel em Administração Pública pela Fundação João Pinheiro.

E-mail: mfernandesnascimento@gmail.com

\section{Henrique Tangari Silva}

\section{iD https://orcid.org/0000-0003-0805-0304}

Mestrando em Administração Pública na Fundação João Pinheiro, Especialista em Gestão de Negócios pela Universidade Federal de Minas Gerais (UFMG) e Bacharel em Administração Pública pela Fundação João Pinheiro.

E-mail: henriquetangari@hotmail.com mudança decorrente da fusão organizacional ocorrida na Secretaria de Estado de Trabalho e Desenvolvimento Social de Minas Gerais entre 2013 e 2014. Monografia; Fundação João Pinheiro; 2014.

SANTOS, Marcel de Souza e Silva. Gestão da mudança organizacional: uma revisão teórica. Dissertação de Mestrado, Escola Brasileira de Administração Pública e de Empresas da Fundação Getúlio Vargas do Rio de Janeiro. 2014.

SePlaG; Plano Plurianual de Ação Governamental 2016 - 2019; Exercício 2019; Volume 2; Anexo II; Programas e Ações por setor de governo; 2018.

SePlag; Plano Plurianual de Ação Governamental 2020 - 2023; Exercício 2020; Volume 1; 2019.

Silva, Marco Antonio Costa da; Araujo, Geraldino Carneiro; VAZ, Telma Romilda Duarte. Gestão por competências como estratégia de mudança organizacional. In: XII SIMPÓSIO DE ADMINISTRAÇÃO DA PRODUÇÃO, LOGÍSTICA E OPERAÇÕES INTERNACIONAIS, 12., 2009, São Paulo. Anais... São Paulo: SIMPOI, 2009.

SouZA, Wertson Brasil de. Interesse público e resistência à mudança em organizações públicas: estudo de casos em uma Secretaria de Estado. 226 f. 1994. Dissertação (Mestrado) Curso de Administração, Departamento de Centro de Pós-graduação e Pesquisa em Administração, Faculdade de Ciências Econômicas, Universidade Federal de Minas Gerais Belo Horizonte: UFMG, 1994. 